\title{
Report \\ Extinction Risk in Successional Landscapes Subject to Catastrophic Disturbances
}

\author{
$\underline{\text { David Boughton }}^{1}$ and Urmila Malvadkar ${ }^{2}$
}

ABSTRACT. We explore the thesis that stochasticity in successional-disturbance systems can be an agent of species extinction. The analysis uses a simple model of patch dynamics for seral stages in an idealized landscape; each seral stage is assumed to support a specialist biota. The landscape as a whole is characterized by a mean patch birth rate, mean patch size, and mean lifetime for each patch type. Stochasticity takes three forms: (1) patch stochasticity is randomness in the birth times and sizes of individual patches, (2) landscape stochasticity is variation in the annual means of birth rate and size, and (3) turnover mode is whether a patch is eliminated by disturbance or by successional change. Analytical and numerical analyses of the model suggest that landscape stochasticity is the most important agent. Landscape stochasticity increases the extinction risk to species by increasing the risk that the habitat will fluctuate to zero, by reducing the mean abundance of species, and by increasing the variance in species abundance. The highest risk was found to occur in species that inhabit patches with short lifetimes. The results of this general model suggest an important mechanism by which climate change threatens biodiversity: an increase in the frequency of extreme climate events will probably cause pulses of disturbance during some time periods; these in turn would cause wider fluctuations in annual disturbance rates and thus increase the overall level of landscape stochasticity. However, the model also suggests that humans can manipulate landscape stochasticity to reduce risk. In particular, if managed disturbances were more evenly distributed in time, attrition of the regional biota might be prevented. Other work on the connection between patch dynamics and extinction risk assumes the absence of landscape stochasticity and thus overlooks an important component of risk to biodiversity.

\section{INTRODUCTION}

Birth-death processes can be considered to operate at a variety of levels of organization in biological systems and are tightly bound up with ideas about the persistence of species. The most familiar level of organization at which births and deaths occur is, of course, that of the individual organism, and the persistence of entire species has traditionally been expressed in terms of the birth rates and death rates at this level. Over the past few decades, it has become useful to broaden the focus and consider "births" and "deaths" at other levels, such as entire populations and even whole habitat patches (Levins 1969, Levin and Paine 1974, Hanski and Gilpin 1997). These birthdeath processes are commonly referred to as metapopulation dynamics and patch dynamics, respectively. Theoretical work on these subjects has tended to focus on deterministic causes of extinction, where a species goes extinct because its only stable equilibrium is at zero abundance (Levins 1969, Johnson 2000, Amarasekare and Possingham 2001). However, ecologists have also recognized that stochasticity in birth-death processes also causes extinction, i.e., that random perturbations of an otherwise persistent species can drive it extinct (MacArthur and Wilson 1967, Levin 1969, Shaffer 1981, 1987). Lande (1993), in particular, thoroughly examined the link between stochasticity and extinction risk at the population level. Hanski (1991) sketched a comparable scheme for metapopulation dynamics.

There is no such treatment for patch dynamics, despite the fact that patch dynamics often encapsulate the dynamics of populations and metapopulations, and despite recent interest in the topic. So far, this interest has focused on deterministic models of extinction (Gyllenberg and Hanski 1997, Johnson 2000, Amarasekare and Possingham 2001). Some studies involved techniques that allowed for stochasticity, such as computer simulations (Fahrig 1992) and interacting particle systems (Keymer et al. 2000); however, because the focus was elsewhere, the role of stochasticity was not examined.

As we see it, there are two important limitations in the work to date. First, patch births in a given landscape are always assumed to be independent of one another,

${ }^{1}$ Pacific Northwest Research Station, U.S. Forest Service; ${ }^{2}$ Princeton University 
in clear contrast to the empirical situation in which climate fluctuations and contagious processes such as fires or floods cause patch births (and deaths) to be correlated in time (O'Neill et al. 1986, Busing and White 1993, Turner et al. 1993, Clark 1993, 1996, Malamud et al. 1998). Are conclusions about species extinction sensitive to this assumption?

Second, the body of work contains heterogenous assumptions about the statistical distribution of death times for patches. Sometimes the assumptions resemble situations in which patch deaths are caused by succession (Fahrig 1992); other times they resemble disturbance (Keymer et al. 2000, Amarasekare and Possingham 2001) or a mixture of the two (Brachet et al. 1999). Are conclusions about extinction sensitive to these assumptions (see also Johnson 2000)?

In this paper, we attempt to address these issues. We treat habitat patches as having discrete births and deaths of their own that arise from the interplay of disturbance and succession. We also examine what would happen if these births and deaths had various probability distributions that corresponded to different mechanisms of landscape change.

To see the potential importance of stochasticity, consider the case of the European grasshopper Bryodema tuberculata. In central Europe, this grasshopper inhabits riparian gravel bars (Stelter et al. 1997). These habitat patches are periodically eliminated by willow invasion and by catastrophic floods that destroy existing patches but also create new ones elsewhere along the river. An important feature of the system is that the turnover of patches is not continuous. Instead, there is an average of three to 10 floods per century, and their sporadic nature tends to create even-aged "cohorts" of gravel bars after each flood (Stelter et al. 1997). As a result, the grasshopper is exposed to two distinct risks: first, the river may go too long without a flood, so that all suitable habitat is lost to willow invasion, and, second, the river may randomly flood several times in quick succession, eliminating the grasshopper populations in the old patches before they can colonize new ones. Either way, the potential exists for the grasshopper to be driven extinct regionally by its patch dynamics. It seems plausible that the risk should depend not just on the number of floods, but also on their distribution in time. If so, water management practices might be adopted to modulate the distribution of floods and reduce risk.
Many landscapes contain multiple species at risk, a more complex situation. For example, west of Austin, Texas, is a landscape that supports two endangered birds: the Black-capped Vireo (Vireo atricapillus) and the Golden-cheeked Warbler (Dendroica chrysoparia). The Warbler is a specialist of old-growth juniper, Juniperus ashei (Engels and Sexton 1994), whereas the Vireo typically inhabits scrub oak thickets, Quercus spp. (Grzybowski et al. 1994). Most stands of scrub oak comprise a mid-successional stage that eventually transforms to juniper; ecological disturbances are necessary to generate new patches or maintain existing ones, but at a cost to patches of juniper. Periods in which the risks of fire or real estate development are high should increase the fraction of scrub oak and decrease that of juniper, whereas rainy economic recessions should do the opposite. Clearly, there is a trade-off between conserving the habitat of one bird species rather than the other. On the other hand, variability in patch turnover might be expected to affect both birds negatively, because it would increase the variability in the amount of both types of habitat. Thus, some management strategies might involve risk trade-offs, whereas others might increase (or decrease) risk across the board. It would be useful to have some insight into the situation. If the risks posed to individual species are modulated by the overall disturbance regime, it may be possible to devise schemes that protect large suites of species via management of the disturbance regime of the system as a whole.

For our purposes here, we abstract to a general scenario of $n$ seral stages that each contain a unique suite of species. The ecological system is idealized as a small number of plant species whose interactions drive succession, plus a larger number of focal species that must passively track this shifting mosaic of patch types (Fig. 1). We examine the persistence of the focal species within the context of the dynamics of the patch mosaic. For our set of focal species, we consider as wide a range of life histories as is practical given the simplicity of the model. This array includes species with rapid population growth, as occurs in many insects, and slow population growth, as occurs in grizzly bears. It includes species with generation times that are short relative to the turnover of their habitat, as might occur in a woodland butterfly or an understory plant with an annual life cycle, as well as those with generation times that are long relative to their habitat, as might occur in the pioneer species that invade a site following a disturbance. Finally, we examine species with high colonization abilities, such as invasive pests, 
and low colonization abilities, such as many epiphytic lichens or other species with low mobility. We ask two general questions. First, how do the dynamics of the patch system affect the extinction risk of a particular species in a particular habitat type? Second, are there risks that cut across all species in all habitat patches?

Fig. 1. A diagram of the succession concept assumed by the model. Successional patches transform into the next stage after a certain number of years. At the terminal stage, the patch is destroyed by disturbance, resetting it to the initial stage. A landscape consists of a population of such patches, which act as a shifting mosaic.

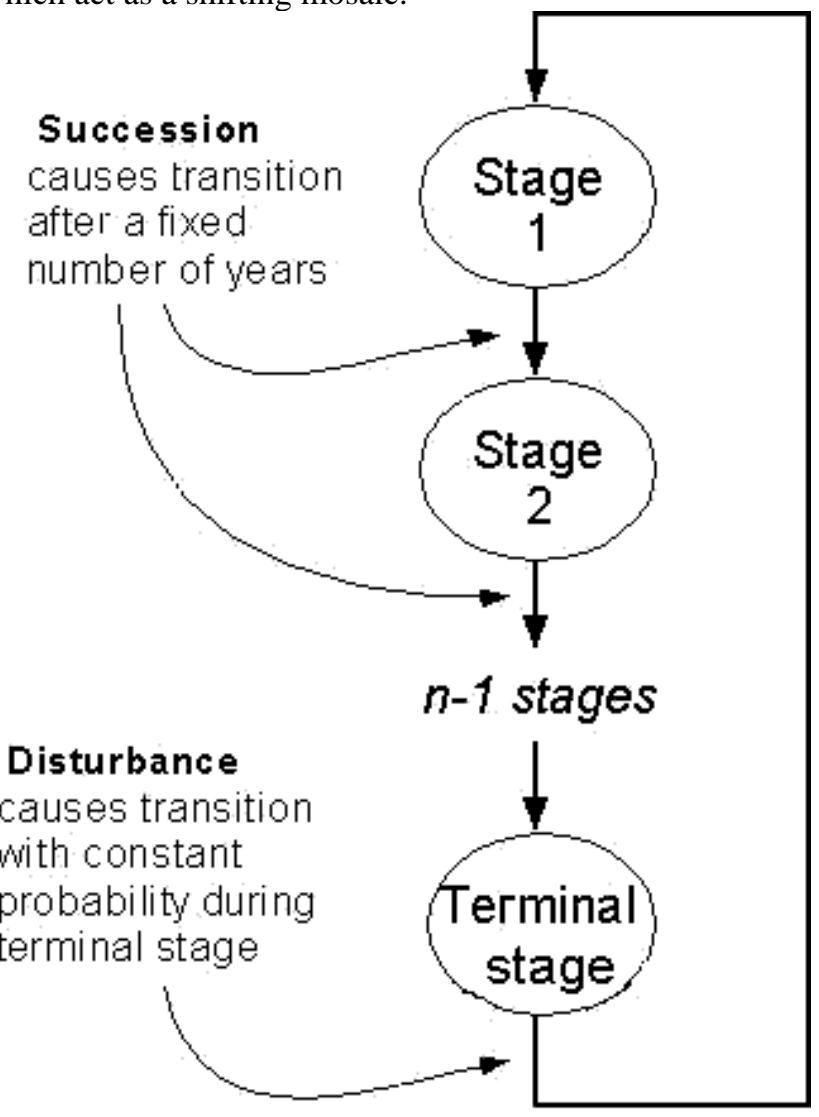

\section{METHODS}

To focus on stochasticity in the patch system, we assumed that birth-death processes were deterministic when operating at the level of populations or metapopulations.

\section{Deterministic model}

A habitat patch is assumed to be a geographic area that intersects with the Hutchinsonian niche, i.e., the set of conditions that permits positive population growth (Hutchinson 1958), for a particular species at some characteristic time during succession. A given patch has two dimensions: a lifetime and a size. We measure size in terms of organisms, i.e., as carrying capacity (Fahrig 1992, Keymer et al. 2000). With the appropriate conversion, size can be interpreted as patch area or even as length for linear habitats such as rivers. Patch lifetime is framed in terms of the generation time of the inhabiting species. A patch's lifetime is the number of generations from its birth to the time that it is destroyed by disturbance or by successional change, i.e., the time when it becomes unsuitable as habitat. For clarity, we will refer to this time unit as "years" rather than "generations," with the understanding that the model can be mentally rescaled without loss of generality.

Under these assumptions, the dynamics of the system can be described by the equation

$$
d M / d t=B-M / S,
$$

in which $M$ is the number of patches on the landscape (Levin and Paine 1974, Paine and Levin 1981). The parameters $B$ and $S$ are the mean birth rate and the mean lifetime of the patches, respectively. If the mean patch size is $A$, then Eq. 1 becomes

$$
d H / d t=A B-H / S,
$$

where $H=M A . H$ represents the total carrying capacity of all the patches in the landscape. In a stationary landscape, $A, B$, and $S$ are constants, and over time the patch system converges to a stable equilibrium, $H^{*}$, that is equal to $B S A$. If the species can move freely from "disappearing" patches to "newly appearing" patches with no mortality cost (a "patchy population" sensu Harrison 1991), then $H^{*}$ represents the landscape's carrying capacity. This means that $H^{*}$ can serve as a common currency for comparing landscapes with different patch dynamics. For example, if one landscape had double the patch size but half the patch birth rate of another landscape, the two would have identical $H^{*}$ values.

\section{Stochasticity}

Next we add stochasticity to the model, in which the births and deaths of patches occur randomly and cause the total amount of habitat to fluctuate. In this case, $H^{*}$ represents mean capacity rather than equilibrium capacity. We represent randomness via three 
categories: (1) patch stochasticity is randomness in the birth times and sizes of individual patches, (2) landscape stochasticity is variation in the annual means of birth rate and size, and (3) the turnover model is the mechanism by which patches are eliminated. The first two categories are parallels of demographic and environmental stochasticity, which are commonly used to describe the demography of individual organisms (Shaffer 1981, 1987, Lande 1993, Foley 1997).

\section{Patch stochasticity}

Assume a landscape in which patch births are discrete events and patch sizes are integers (i.e., can contain only integer numbers of organisms). If patch births are independent of one another, patch births per year are Poisson distributed with mean $B$. Likewise, if the reproductive sites or territories of a patch are independently generated by the event that gave rise to the patch, then patch sizes are Poisson distributed with mean $A$. In this construction, patches with size zero are possible; they represent patches that possess the characteristics of habitat but are too small to support even a single organism. The probabilities of zero births and zero size are $\operatorname{Pr}\left[b_{i}=0\right]=e^{-B}$ and $\operatorname{Pr}\left[a_{i, j}=0\right]=e^{-A}$, respectively.

Patch stochasticity is a factor in the models of Keymer et al. (2000) and Fahrig (1992) because they both used discrete-space models. However, neither paper focused on the consequences of patch stochasticity; in fact, Fahrig used an algorithm to dampen it.

\section{Landscape stochasticity}

Landscape stochasticity is a lack of independence among birth events or patch sizes that causes their distributions to depart from the Poisson. Ultimately, the lack of independence arises from disturbance processes that tend to fluctuate from year to year. Most disturbances, e.g., hurricanes, fires, world wars, tend to be aggregated into certain times and places and are "clumped" relative to the Poisson distribution. These can be represented mathematically by the negativebinomial distribution (Southwood 1966, Hilborn and Mangel 1997, Young and Young 1998).

The negative-binomial distribution can be specified by a mean and a dispersion parameter $u$. Following Young and Young (1998), we adopt a parameterization in which the negative-binomial converges onto the Poisson as $u$ goes to zero. Larger values of $u$ imply higher levels of year-to-year variability. The probability of drawing zeros from this distribution is

$\operatorname{Pr}\left[b_{i}=0\right]=\left(1+u_{B} B\right)^{-1 / u_{B}}$ and $\operatorname{Pr}\left[a_{i, i}=0\right]=\left(1+u_{A} A\right)^{-1 / u_{\lambda}}$

We examine three levels of aggregation: (1) reference (patch stochasticity only), (2) low variability (dispersion parameter $u_{A}$ or $u_{B}$ equal to 1 ), and (3) high variability $\left(u_{A}\right.$ or $u_{B}$ equal to 10$)$. To get an idea of the meaning of each level, consider a system in which the mean birth rate is 100 patches per year. What is the probability of a year with zero patch births? Under reference variability, the probability is extraordinarily small $\left(3 \times 10^{-44}\right)$. Under low variability, the probability rises to 0.01 , and the shape of the distribution is similar to some of the power laws that describe selforganized critical behavior (e.g., Malamud et al. 1998). Under high variability, the probability is 0.50 , and all the patch births occur in only half the years.

\section{Turnover mode}

Finally, we define distributions for patch lifetime, representing succession and disturbance (Fig. 1). The succession mode assumes an orderly set of changes in the plant community that eventually transforms the patch into nonhabitat. Under this idealization, all patches have identical lifetimes, subject to the constraint that they be integers. For example, if mean lifetime is $10.5 \mathrm{yr}$, in our model actual lifetimes of 10 $\mathrm{yr}$ and $11 \mathrm{yr}$ each occur with probability 0.50 .

In contrast, the disturbance mode assumes patches to have a constant risk of destruction. This implies a geometric distribution of lifetimes; for example, if a risk of $10 \%$ is applied to a cohort of 1000 patches, then 100 patches disappear in year 1 , leaving 900 , and 90 disappear in year 2 , leaving 810 , and so on. In this mode, most patches have lifetimes shorter than the mean, but a few have lifetimes much longer. The mean itself is the reciprocal of the rate of disappearance. These assumptions relate to previous work in the following way. Fahrig (1992) assumed a fixed patch lifetime corresponding to our succession mode. Keymer et al. (2000) and Amarasekare and Possingham (2001) assumed constant rates that correspond to our disturbance mode but are modeled in continuous time rather than discrete time. Brachet et al. (1999) assumed a mixed model: maximum lifetime was fixed, as in our succession mode, but patches had a constant risk of being destroyed sooner, as in our disturbance mode. 


\section{Risk factors}

We consider three indicators of extinction risk: (1) decreases in the mean abundance of species, (2) increases in the variance of abundance, and (3) increases in the probability that habitat will fluctuate to zero, leaving a gap in the continuity of habitat. For convenience, we will call these the "mean," "variance," and "gap" effects, respectively. These effects were estimated for various levels of landscape stochasticity and expressed in proportion to their levels in a reference landscape. The reference landscape lacked landscape stochasticity but was otherwise identical to the focal landscape (see Table 1). For example, a mean effect of 0.4 indicates that the mean abundance of a species in the focal landscape was reduced by $40 \%$ compared to its reference. A variance effect of 2 indicates that the standard deviation of the species abundance was doubled relative to its reference.

Table 1. Indicators of extinction risk. Effect size is measured in relation to a reference landscape lacking landscape stochasticity.

\begin{tabular}{lll}
\hline Name & \multicolumn{1}{c}{ Description } & \multicolumn{1}{c}{ Effect size } \\
\hline Gap effect & $\begin{array}{l}\text { Probability of a gap in the } \\
\text { continuity of habitat }\end{array}$ & $\begin{array}{l}\text { The multiplier of patch birth rate necessary } \\
\text { to counteract the increased risk of a gap }\end{array}$ \\
Mean effect & $\begin{array}{l}\text { Reduction in a species' } \\
\text { mean abundance }\end{array}$ & $\begin{array}{l}\text { The proportion by which } \\
\text { the mean decreases }\end{array}$ \\
Variance effect & $\begin{array}{l}\text { Increase in a species' standard } \\
\text { deviation of abundance }\end{array}$ & $\begin{array}{l}\text { The factor by which the standard } \\
\text { deviation increases }\end{array}$ \\
\hline
\end{tabular}

For reasons that will become apparent in the results, we expressed the gap effect as the increase in patch birth rate that was required to keep the risk of a gap below 0.05. Again, this is expressed in relation to a comparable reference landscape,

gap effect $=\frac{B \text { such that } \operatorname{Pr}[\text { Habitat }>0] \text { is } 0.95 \text { in the focal landscape }}{B \text { such that } \operatorname{Pr}[\text { Habitat }>0] \text { is } 0.95 \text { in the reference landscape }}$.

Thus, a gap effect of 10 indicates that the patch birth rate would have to be increased 10 -fold to compensate for the risk arising from landscape stochasticity.

\section{Population models}

The gap effect could be determined analytically; the derivations of the various models are in Appendix 1. To estimate the mean and variance effects, it was necessary to perform numerical simulations of a population model that was embedded within the patch model (please refer to the methods in Appendix 1). Given the many possible population models, we examined two simple ones that are complementary to one another: a patchy population and a metapopulation. In the patchy population, the organisms disperse freely between habitat patches (Harrison 1991), and the population is assumed to have finite growth each generation. The population grows according to the equation

where $\lambda_{\text {is }}$ the finite rate of increase and $H_{t+1}$ is the amount of habitat in year $t+1$. In the metapopulation model, dispersal between patches is restricted, but

$$
N_{t+1}=\operatorname{Min}\left(\lambda N_{t}, H_{t+1}\right)
$$

population growth is effectively infinite: a subpopulation fills a patch to capacity immediately after colonization (see Levins 1969, Hanski 1994). Under these assumptions, the probability of a patch being occupied is

$$
p_{i, t+1}=p_{i, t}+\left(1-p_{i, t}\right)\left(1-\prod_{i}^{M} 1-p_{i, t}\left(1-(1-c)^{a_{i}}\right)\right), j \neq i
$$

where $c$ is the colonization probability (the probability that an organism in patch $j$ will send out propagules that successfully colonize patch $i$ the following year (see Appendix 1). Expected total abundance of the 
species in year $t$ is $\sum p_{i, t} a_{i, t}$. The model assumes each subpopulation to persist until its patch disappears. For both models, we used simulations to examine a low, medium, and high value of the relevant demographic rate $(\lambda=1.01,1.25$, and 2.0 , and $c=0.00001,0.001$, and 0.1$)$.

In toto, we considered an array of species with widely varying characteristics, namely, association with longlasting patches vs. ephemeral patches (relative to species' generation time), large vs. small patches (relative to species' home-range size or territory size), patches destroyed by succession vs. disturbance, species with high vs. low population growth (a doubling per generation vs. a $1 \%$ increase per generation), and high vs. low colonization ability (covering four orders of magnitude, which should suffice for a parameter whose empirical range of values is still poorly known).

\section{RESULTS}

\section{Habitat discontinuities under patch stochasticity}

Under patch stochasticity, there was a sharp threshold in the probability that the amount of habitat would be greater than zero in a random year. At high patch birth rate or size, this probability was very close to 1 . As either parameter was reduced, the probability eventually encountered a threshold at which it quickly dropped to nearly zero, indicating that extirpation of the species became very likely (see Fig. 2 for an example). For convenience, we assess the position of this drop via the "critical" threshold, defined as the contour at which the probability of habitat is 0.95 (Fig. 2 ). The critical threshold is described by the equation

$$
B=\frac{\ln (0.05)}{S\left(e^{-A}-1\right)}
$$

for both the succession and disturbance modes. The derivation of Eq. 7 is described in Appendix 1.
Fig. 2. The probability that a habitat will remain above zero in a random year. Shown is the case for successional patches with a mean lifetime of $3.1 \mathrm{yr}$ and no landscape stochasticity $\left(u_{A}=u_{B}=0\right)$. The probability has a threshold whose position is quantified via the "critical threshold," which is equal to the 0.95 contour on the probability surface. Low risk occurs above the contour, high risk below.

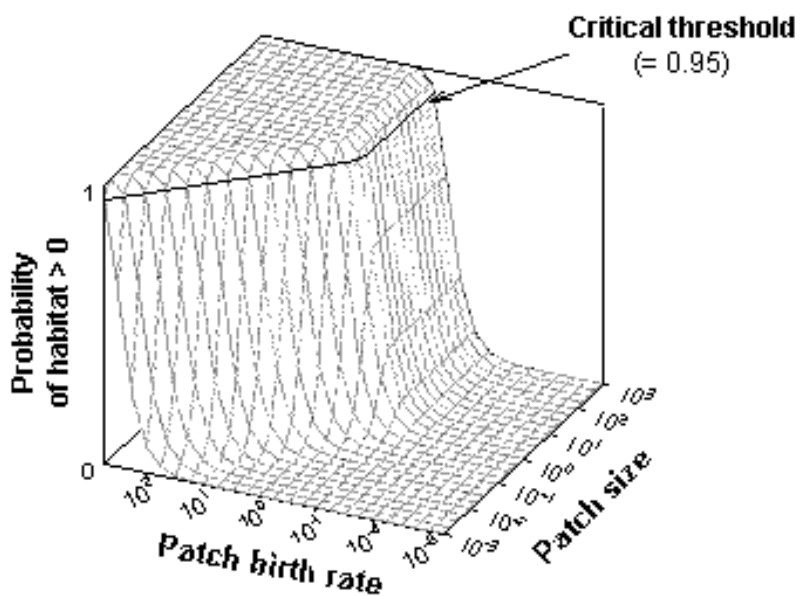

Fig. 3. The position of critical thresholds in four kinds of patchworks. Patch lifetimes are equal to 3.1, 10, 31, and 100 $\mathrm{yr}$, respectively; model assumptions are succession and zero landscape stochasticity. The shape of the critical threshold is similar among cases, but its position on the axes varies according to patch lifetime. For a system at point a, mean capacity $\left(H^{*}\right)$ can be reduced by decreasing either the patch size (horizontal arrow) or the patch birth rate (vertical arrow). Both options carry equal risk in that they are equidistant from the critical threshold. However, for a system at point $\mathbf{b}$, it is always riskier to reduce the patch birth rate.

\section{Critical thresholds compared}

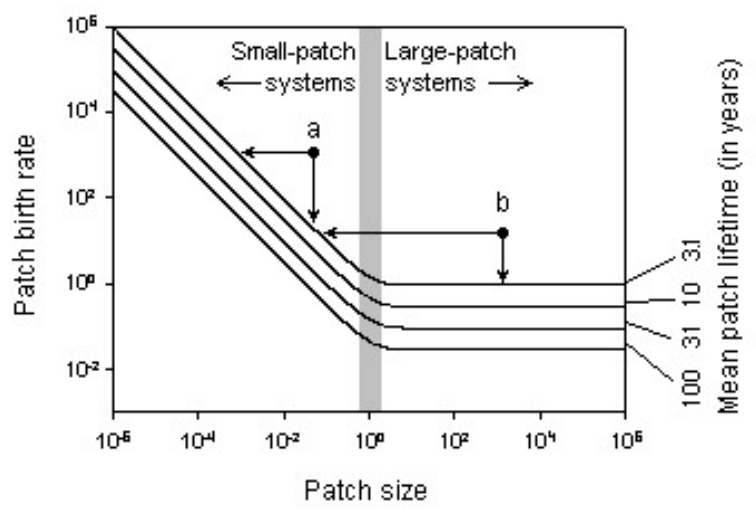


Figure 3 illustrates the shape of the threshold in parameter space. Observe that, in the left-hand part of the figure where patches are small, this threshold is approximated by a diagonal line with slope -1 (proven analytically in Appendix 1). In contrast, on the righthand side of the figure where mean patch sizes are larger (>2), the threshold is independent of patch size (also shown analytically in Appendix 1). Figure 3 also illustrates the fact that the critical threshold depends on patch lifetime. Its shape is preserved as lifetime becomes longer, but its position shifts down the $B$ axis so that systems with longer patch lifetimes can tolerate greater reductions in patch birth rate. In large-patch systems, the relationship is simple: the species stays above the threshold if $B>\ln (20) / S$.

Fig. 4. The effect of landscape stochasticity on the position of the threshold. The reference curve is the critical threshold shown in Fig. 2 (successional patches with lifetime $=3.1$ yr). The middle curve is the critical threshold for similar landscapes differing only in that they have high variability in patch sizes $\left(u_{A}=10\right)$. The upper curve is the critical threshold for landscapes that have high variability in patch births per year $\left(u_{B}=10\right)$. The lengths of arrows $\mathbf{a}$ and $\mathbf{b}$ are examples of gap effects for particular scenarios.

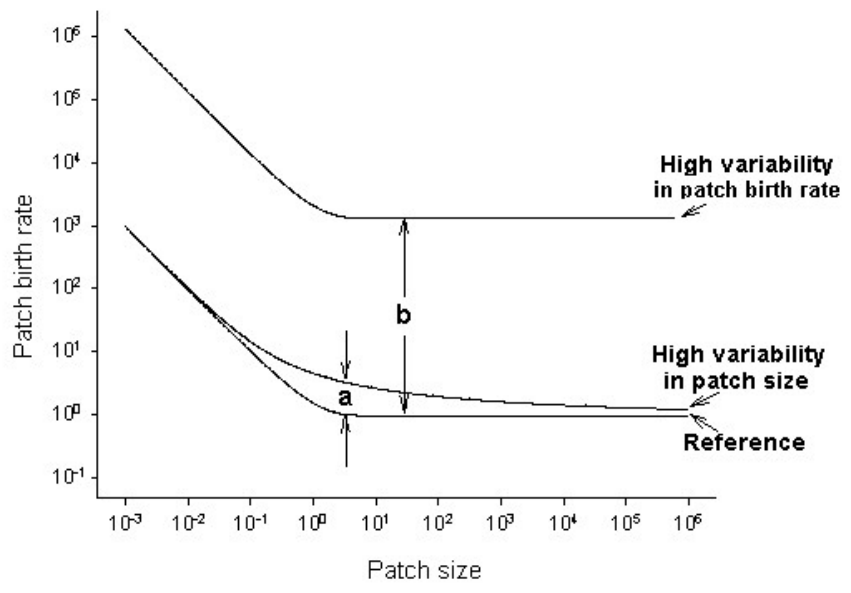

\section{Gap effects and landscape stochasticity}

From the derivations in Appendix 1, it was possible to calculate exact values for the gap effects at various levels of landscape stochasticity, although the equations involved were sometimes messy. The largest gap effect occurred in successional patches with short lifetimes $(<5 \mathrm{yr})$, and the cause was high variability in patch birth rate (Fig. 4). For example, in patches with a mean lifetime of $3 \mathrm{yr}$, the threshold $B$ was 1.00 patches per year in the reference landscape and 2172 patches per year in the landscape with high variability. This implies a gap effect of 2172, more than three orders of magnitude! (See arrow $\mathbf{b}$ in Fig. 4.)

Fig. 5. Gap effects in a variety of large-patch systems, in which the size of the effect is measured in relation to a reference landscape that lacks landscape stochasticity. Low variability is $u_{A}=1$ (for variability in patch size) or $u_{B}=1$ (for variability in patch births). Medium variability is $u_{A}=5$ or $u_{B}=5$, and high variability is $u_{A}=10$ or $u_{B}=10(A=10$; results were similar for larger $A$ except that the effects of $u_{A}$ become smaller).

A) Successional patches

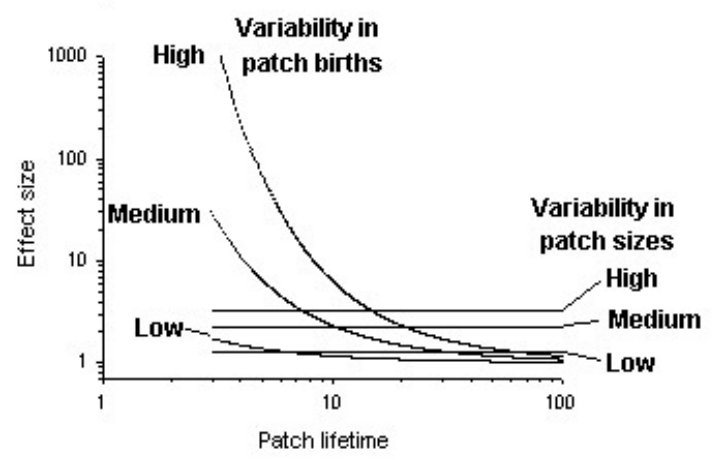

B) Disturbance patches

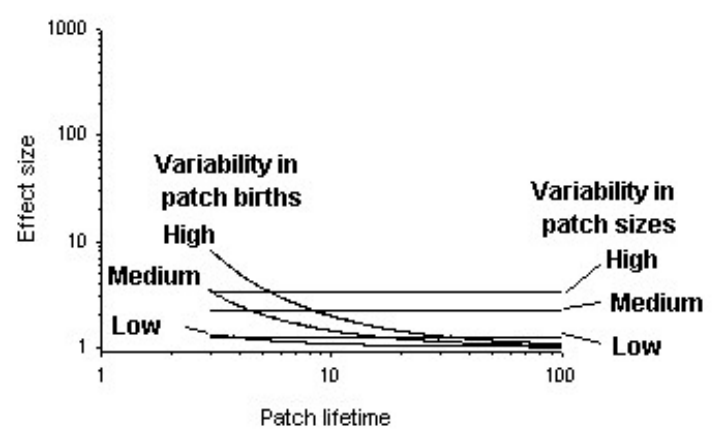

Effect sizes of other parameter combinations were smaller but nonetheless notable. For the case of largepatch systems $(A>2)$, the results are as follows (see Fig. 5):

1. Gap effects were consistently greater than 1.0, implying that landscape stochasticity generally increased the risk of extinction. The magnitude of the increase could be quite small or large. 
2. Birth rate fluctuations caused large gap effects, especially in the most ephemeral patch types. Long-lived patches ( $S=100 \mathrm{yr}$ ) were much less susceptible to landscape stochasticity, and effect size was always less than 1.17 , meaning that patch birth rate would have to be increased only $17 \%$ to control risk even under very high fluctuations (see Fig. 5).

3. Birth rate fluctuations had consistently larger effects in succession mode than in disturbance mode by factors ranging from 1.004 to more than 30 depending on lifetime (compare parts A and B of Fig. 5).

4. When patch size rather than birth rate was variable, gap effects were independent of lifetime and differed little between the succession and disturbance models. They were relatively small, but nevertheless dominated in long-lived patches $(S=100 \mathrm{yr})$. Figure 5 shows the case for $A=10$; the effects become smaller with larger patches.

Fig. 6. A profile of habitat occupancy in a typical patchy population $(\lambda=1.1$, patch size $A=10)$. Shown is a disturbance model with short patch lifetimes (3.1 yr). Habitat occupancy is the mean proportion of habitat occupied by the species over time.

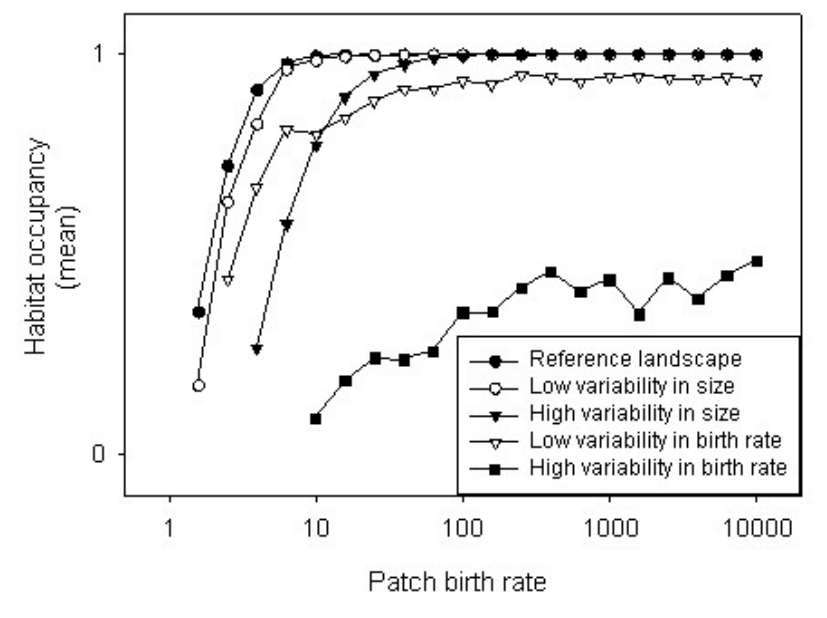

Thus, in large-patch systems a change in patch size (mean or dispersion) generally had a relatively small effect, but a change in patch birth rate could have a large effect. Reducing the mean or increasing the dispersion could push the system over the critical threshold of risk.

\section{Mean and variance effects}

The results from the population simulations are as follows. First, we examined the effect of simple changes in patch birth rate. Figure 6 shows profiles for a set of landscapes as their patch birth rate was changed; this pattern is typical of the various parameter combinations we examined. The vertical axis of the graph shows habitat occupancy, which is the mean of population size divided by amount of habitat. Occupancy tended to be depressed near the critical threshold, but it increased with higher patch birth rates. Thus, near the threshold, an increase in patch birth rate not only raised the mean amount of habitat $\left(H^{*}\right)$ but also tended to increase the fraction of the habitat that was occupied by the species.

Fig. 7. The mean and variance effects when patch sizes were variable: $u_{A}=1$ (low), and $u_{A}=10$ (high). Larger effects imply higher risks of species extinction. The horizontal curves illustrate effects for species with medium demographic rates $(\lambda=1.25$ for patchy populations, and $c$ $=0.001$ for metapopulations). The vertical lines illustrate the range of effects observed under high and low demographic rates $(\lambda=1.01-2.0$, and $c=0.1-0.00001)$. For the mean effect, effect size was always close to zero, and there was virtually no spread among the different demographic rates. For the variance effect, effect size was only negligible in species with low demographic rates $(\lambda=$ $1.01, c=0.00001$; not labeled in figure), or in patches with long lifetimes and disturbance as the mechanism of turnover.

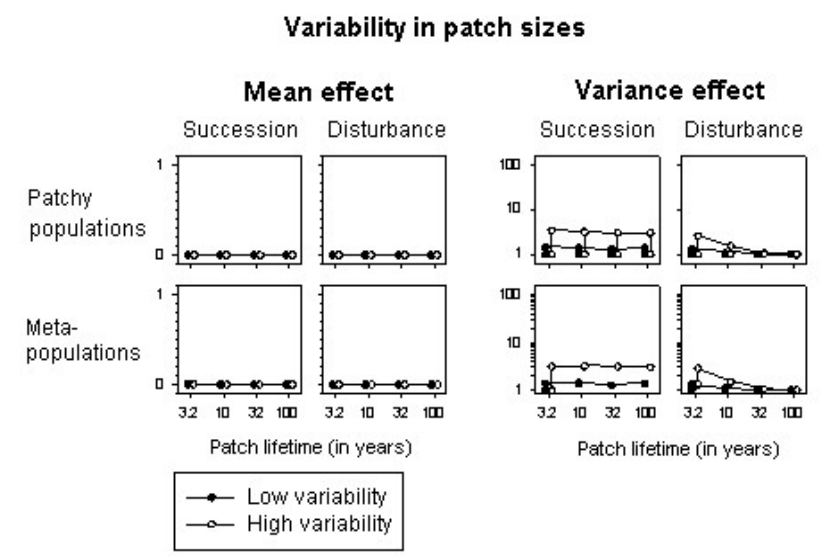

Next we examined risk in systems that were well above their critical thresholds by simulating landscapes with $B=10,000$ patch births per year and 
calculating the mean and variance effects for species with high, medium, and low demographic rates, respectively (Figs. 7 and 8). Several patterns became evident.

Fig. 8. The mean and variance effects when patch birth rate is variable: $u_{B}=1$ (low), and $u_{B}=10$ (high). Larger effects imply higher risks of species extinction. The horizontal curves illustrate effects for species with medium demographic rates $(\lambda=1.25$ for patchy populations and $c=$ 0.001 for metapopulations). The vertical lines illustrate the range of effects observed under high and low demographic rates $(\lambda=1.01-2.0$, and $c=0.1-0.00001)$. For the mean effect, the spread among demographic rates within a patch type was very small when patches were long-lived. When patches were short-lived, the spread was wider, as can be observed in the figure. In these cases, the largest effects were in the species with the lowest demographic rates $(\lambda=$ 1.01, and $c=0.00001$; not labeled in figure). For the variance effect the situation was reversed: when spread occurred, the smallest effect was in the species with low demographic rates (not labeled in figure). This is partly an artifact of the simulation method (see Discussion).

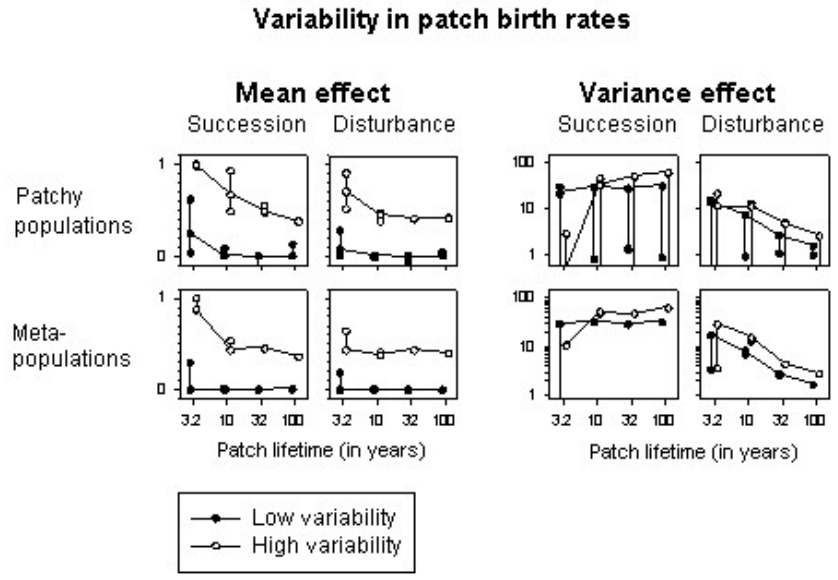

\section{Variability in patch size}

Variability in size generally had no effect on the mean abundance of species in the entire range of demographic rates examined (Fig. 7). Variance effects were larger. Low variability increased the standard deviation of species abundances by up to $30 \%$. High variability increased it by up to $300 \%$ (Fig. 7). In succession models, variance effects were independent of patch lifetime. In disturbance models, they were inversely related to patch lifetime.

\section{Variability in patch birth rate}

Mean effects could be quite large in the case of variable birth rate (Fig. 8). Low variability reduced mean abundance by 0 to $70 \%$, depending on patch lifetime and species demographic rates. High variability reduced it by 40 to100\%. The largest effects tended to occur in the patches with the shortest lifetimes.

Variance effects were also quite strong. Low variability in patch birth rate increased the standard deviation of species abundance by up to 30 -fold; high variability increased it by up to 60 -fold (Fig. 8). Once again, in successional mode the variance effects were relatively insensitive to patch lifetime, whereas in disturbance mode they were smaller in the longer-lived patches.

It can be seen in Fig. 7 and especially in Fig. 8 that, within a given patch category, there was some spread that occurred in the mean and variance effects, as indicated by the symbols connected by vertical lines. This spread is the range for species with high and low demographic rates, respectively (see the figure legends for details). It could be quite pronounced when patch birth rates were variable (Fig. 8). For the mean effect, the largest effects occurred in the species with the smallest demographic rates $(\lambda=1.01, c=0.00001)$, corresponding to species with slow growth or poor colonization ability. Conversely, the smallest effects were in species with large demographic rates $(\lambda=2, c$ $=0.1$ ), i.e., those with rapid growth or good colonization ability. These results are intuitive. Less intuitive is the variance effect, in which the situation was the opposite: species with small demographic rates had the smallest effects. Sometimes their effects were less than one, indicating lower variability than in the reference system.

\section{DISCUSSION}

The critical threshold had several interesting properties related to patch stochasticity. In the small-patch portion of parameter space the threshold had a slope of -1 (left side of Fig. 3). This implies that reducing the patch size carries the same risk as reducing the patch birth rate. For example, cutting the mean patch size in half has the same risk as cutting the patch birth rate in half. This equivalence can be deduced geometrically from Fig. 3; any small-patch system is equally as far to the right of the threshold as it is above the threshold (e.g., point a in Fig. 3). 
In contrast, in large-patch systems the risk is independent of patch size (right side of Fig. 3). Consider a hypothetical scenario in which land managers must reduce the mean capacity of a landscape $\left(H^{*}\right)$, but do not want to extirpate any species in the process. In large-patch systems, reducing the patch birth rate is always riskier than reducing the patch size, because the former always encounters the critical threshold sooner (compare the horizontal and vertical arrows at point $\mathbf{b}$ in Fig. 3).

One of the most important predictions suggested by these results is that landscape stochasticity can be a strong force for species attrition. These risks were found to be the highest in the most ephemeral habitats, a view consistent with certain empirical observations (Menges 1990, Thomas and Morris 1994). The model predicts that variable birth rates tend to have larger effects than variable patch sizes. Fluctuating birth rates added to risk by raising the probability of habitat fluctuating to zero, by tending to reduce the mean abundance of species, and by increasing the magnitude of abundance fluctuations. These conclusions cut across most of the species types.

There was, however, one set of circumstances in which fluctuating patch birth rates seemed to be beneficial: variance effects of less than 1 were observed in species with low demographic rates, i.e., poor colonization ability or slow population growth. A variance effect of less than 1 meant that the species fluctuated less than in the reference landscape, which is counterintuitive. Inspection of the individual model runs indicated that these species were buffered against habitat fluctuations, but only on the upside; they failed to grow quickly when the amount of habitat suddenly increased in a highly variable situation. In other words, in a boom-and-bust landscape they were hurt by the bust but not helped by the boom, and thus they were less variable than species that could rapidly exploit the boom because of high demographic rates. In short, for species with low resiliency and thus low variability, landscape stochasticity was not at all beneficial.

\section{Implications}

To explore some implications of our results, think of patch birth rate as a linear function of landscape size, $B=k L$, where $k$ is patch births per unit area and $L$ is the size of the entire landscape. If $k$ is everywhere the same, an increase in $L$ reduces risk across all species. This prediction is consistent with island biogeography theory, which predicts that larger islands will have lower extinction rates and higher species diversity (MacArthur and Wilson 1967). Because habitat diversity is only one mechanism among the many that have been proposed to account for this pattern (MacArthur and Wilson 1967, Pickett and Thompson 1978, Quinn and Harrison 1988, Holt 1992, Foley 1997), it has tended to receive little attention. However, Picket and Thompson (1978) described its relevance early on, noting that habitat diversity is maintained dynamically by disturbance and succession. To avoid extinctions, they suggested that an island must have the "minimum dynamic area," i.e., the smallest area in which the disturbance regime is capable of maintaining all habitats at all times. Our theoretical analysis builds on their concept by predicting that the minimum dynamic area should depend on landscape stochasticity (Fig. 9). Applying this insight to conservation problems, we suggest that species attrition might be prevented by manipulating the dynamics of patch births and/or deaths.

Fig. 9. The concept of landscape stochasticity in the context of island biogeography theory. The island-wide "gap" effect for a species shows an approximate power relationship with island size. The slope of the relationship is related to variability in the patch birth rate. The three dots mark the location of critical thresholds on each curve, indicating the points at which it becomes highly unlikely that the species can persist on the island for even a short time.

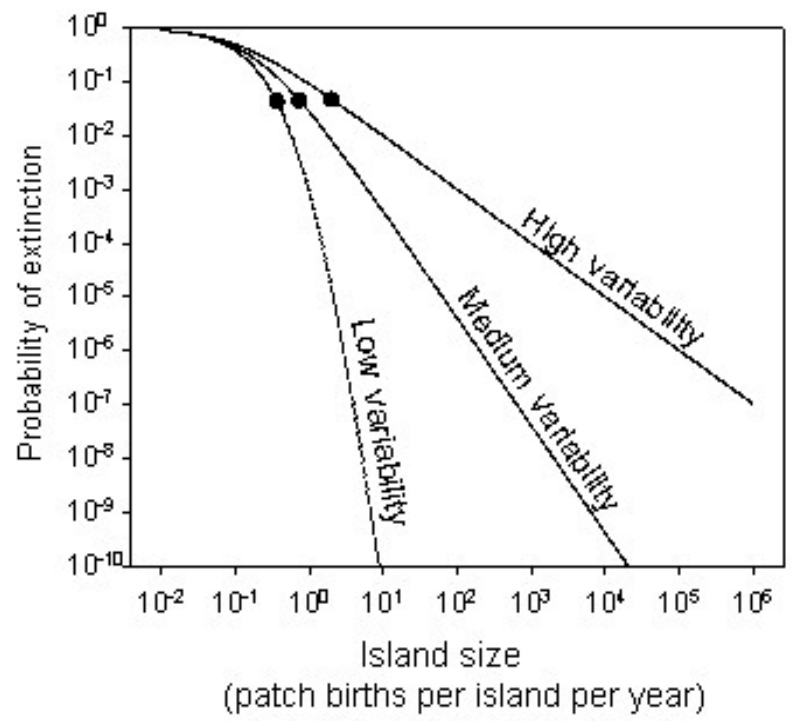

In many areas, land managers are already manipulating patch dynamics ad hoc. For example, the Coast Range Mountains in the state of Oregon comprise $2 \times 10^{6}$ ha whose ownership is distributed 
among federal and state agencies, large corporate timber companies, and small private holdings. Recently, several old-growth preserves were established on the federal lands to protect old-growth specialists, including the endangered owl Strix caurina occidentalis (U.S. Forest Service and U.S. Department of the Interior 1994). The preserves were established because the amount of old-growth had dwindled to 5\% of the region's area. To place this state of affairs in context, Wimberly et al. (2000) reconstructed the province's prehistoric fire regime. Using charcoal records and a simulation model, they inferred that wildfire originally caused a shifting mosaic of patch types in which the proportion of old-growth forest varied from 25 to $70 \%$ of the landscape. At a smaller scale equivalent to the size of today's old-growth reserves, the proportion varied from 0 to $100 \%$. This suggests that today's reserves are smaller than the region's minimum dynamic area. Consequently, active fire suppression is necessary to prevent extirpation of old-growth specialists (U.S. Forest Service and U.S. Department of the Interior 1994).

We suggest that the Coast Range situation has arisen because of the territorial behavior of human groups: property lines now delineate disturbance regimes, which are dominated by rotational timber harvest on private lands, structure-based management on state lands, and fire suppression on federal lands (Spies et al., in press). Each of these regimes represents a different compromise between conflicting environmental and economic world views. In the context of our model, this is a shift from a system in which patch birth rate had not only a large mean but also a large variance (i.e., large areas of old growth but also high landscape stochasticity due to catastrophic fires) to a system in which its mean is small and its variance is also small (i.e., the potential for old growth exists only on federal and perhaps state lands and mean fire size is vastly reduced). The prehistoric and contemporary situations are two points along a continuum of schemes that could be envisioned to trade off the risks imposed by the mean amount of habitat with the risks imposed by landscape stochasticity. For those who might evaluate the many possible schemes, our results lead us to offer the following speculations for consideration:

1. Structure-based management is often used to "accelerate" succession by actively managing for, say, old-growth characteristics in forest stands that are relatively young. This shortens the patch lifetimes of intervening seral stages or eliminates the intervening stages entirely (i.e., reduces their patch birth rate). Our model predicts that these effects can potentially increase the risk to species specialized on those seral stages. Thus, there are likely to be inherent trade-offs between specialists of different seral stages. Increasing the mean amount of habitat for one group probably decreases the mean for another.

2. However, the extinction risk from reducing patch lifetime or birth rate depends on how close the species already is to its extinction threshold. If it is far away from the threshold, the change in risk may be infinitesimally small. Thus, choosing a scheme requires some understanding of the demography of individual species. This might be gained by studying either the demography of a representative group of species scattered among various patch types, or by reviewing the long-term history of disturbance to infer what their demography must have been to persist in the system up to the present day.

3. In contrast to the trade-offs described above, landscape stochasticity had a consistent effect across all types of species in all patch types. It always increased risk, although the increase ranged from negligible to catastrophic (Figs. 5,7 , and 8 ). This suggests that increasing the level of landscape stochasticity relative to prehistoric levels would entail risks to many species, whereas decreasing it would probably be risk-free. Because the effect cuts across all species in a consistent way, it seems reasonable to expect that a conservation plan that focuses on landscape stochasticity would tend to protect assemblages of poorly known species with relatively high efficiency.

It also seems possible that the concept of landscape stochasticity is relevant to ecosystem management in an era of global climate change. The world's climatologists have reached consensus that human activities are causing rapid global warming (Intergovernmental Panel on Climate Change 2000, 2001), and it is widely believed that the increased thermal energy in the climate system will produce more droughts, floods, and wildfires (Easterling et al. 2000). Such a turn of events will probably increase the level of landscape stochasticity in many areas, even as human activities fragment the remaining "natural" areas. 
Against this troubling backdrop, it is interesting to contemplate the conservation opportunities in working landscapes. For example, recent advances in applied forestry emphasize ecological values, including the value of biodiversity (Kohm and Franklin 1997). Moreover, the concept of historical variability is increasingly used to frame environmental issues in working landscapes and river systems (Attiwill 1994, Swanson et al. 1994, Frissell and Bayles 1996, Aplet and Keeton 1999, Boughton et al. 1999, Everett and Lehmkuhl 1999). Resource managers have begun using historical data to develop new management practices that partially mimic the original disturbance regimes (Cissel et al. 1999, Landres et al. 1999). These developments suggest that historic disturbance regimes can be the basis for managing "populations" of patch types at a truly regional scale (Baker 1992, Benda et al. 1995).

Unfortunately the changing climate will ultimately push many systems outside their historic ranges, and existing concepts are heuristic and offer little guidance in managing the novel situations of the coming century. Our model suggests the possibility of managing patch systems according to principles of population biology as applied to patches rather than organisms. Here we have examined one of the simplest possible models, but future work might profitably focus on more complex models involving concepts of population regulation. This is often defined as fluctuations within limits, in which the lower limit is greater than zero (Mountford 1988, Murdoch and Walde 1989, Hanski 1990). It is interesting that the hierarchy theory of ecosystems has a parallel concept of "incorporation" that describes the regulation of ecosystem attributes (O'Neill et al. 1986). Because the amount of habitat is such an attribute, it may be worthwhile to examine how incorporation concepts can be applied to biodiversity management. By doing so, ecological systems may be able to depart from their historic regime in ways that minimize risk for as much of the biota as possible, provided that economic and ecological values are adequately integrated into the working parts of the landscape.

Responses to this article can be read online at: http://www.consecol.org/vol6/iss2/art2/responses/index.html.

\section{Acknowledgments:}

We thank R. Busing, T. Spies, F. Swanson, and M. Wimberly for critiquing the manuscript. A quantity of anonymous reviewers and editors at Conservation Ecology provided comments and criticisms that were very helpful for clarifying the ideas herein. Boughton thanks the USDA Forest Service and the National Marine Fisheries Service for support, and Malvadkar for conveying the discrete charm of the PDF.

\section{APPENDIX 1. DERIVATION OF EQUATIONS AND NUMERICAL METHODS}

\section{Derivation of the gap effect}

Assume that the landscape is such that, in year $i$, the number of patch births $b_{i}$ is either Poisson distributed with mean $B$, or negative-binomially distributed with mean $B$ and dispersion parameter $u_{B}$. Likewise, the size of each patch $a_{i, j}$ ( $j=1$ to $\left.b_{i}\right)$ is either Poisson distributed with mean $A$, or negative-binomially distributed with mean $A$ and dispersion parameter $u_{A}$. The Poisson distribution is a model of patch stochasticity; the negative binomial is a model of patch + landscape stochasticity.

In the negative binomial distribution, the mean and dispersion parameters $(X, u)$ are related to the conventional parameters $p$ and $m$ as

and

$$
p=(1+u X)^{-1}
$$

$$
m=u^{-1} \text {. }
$$

According to the relevant probability distribution functions (PDFs), the probability of zero patch births in year $i$ under the Poisson distribution is 


$$
\operatorname{Pr}\left[b_{i}=0\right]=e^{-B}
$$

or the negative-binomial distribution

$$
p^{m}=(1+u B)^{-1 / u} .
$$

Notice that Eq. A.3 is equal to the limit of Eq. A.4 as $u$ approaches zero. Analogous equations describe the probability of patches with size zero.

\section{Succession model with lifetime $S$}

Case 1: $a_{i, j}, b_{i}$ are Poisson distributed with means $A$ and $B$. Let $H=H(t)=$ a random variable describing total habitat present at time $t$.

$$
H=\sum_{i=i-g}^{t} H_{i}
$$

where $H_{i}$ is the amount of habitat added in year $i(S$ an integer). Let $I$ be the probability that there is no habitat at time $t$, that is,

$$
\begin{aligned}
& I=\operatorname{Pr}[H=0] \\
& =\operatorname{Pr}\left[H_{i}=0 \text { for } i=t-S, t-S+1, \ldots t\right] \\
& =\operatorname{Pr}\left[H_{t-S}=0\right] \operatorname{Pr}\left[H_{t-S+1}=0\right] \ldots \operatorname{Pr}\left[H_{t}=0\right] \\
& =\left(\operatorname{Pr}\left[H_{i}=0\right]\right)^{S},
\end{aligned}
$$

in which distributions are independent of time.

The probability for each individual year is

$$
\begin{aligned}
\operatorname{Pr}\left[H_{i}\right. & =0]=\sum_{x=0}^{\infty} \operatorname{Pr}\left[a_{i, i}=0 \text { for all } j \mid b_{i}=x\right] \operatorname{Pr}\left[b_{i}=x\right] \\
& =\sum_{x=0}^{\infty} e^{-A} e^{-A} \ldots e^{-A}\left(e^{-B} B^{x} / x !\right) \quad \text { (there are } x a_{i, i}{ }^{\prime} s \text { ) } \\
& =\sum_{x=0}^{\infty} e^{-x A}\left(e^{-B} B^{x} / x !\right) \\
& =e^{-B} \sum_{x=0}^{\infty}\left(e^{-A} B\right)^{x} / x ! \\
& =e^{-B} e^{B e^{-A}}=e^{B\left(e^{-A}-1\right)}
\end{aligned}
$$

The probability for all years is therefore

$$
I=\left(\mathrm{e}^{B\left(\mathrm{e}^{-k}-1\right)}\right)
$$

If $S$ is not an integer, a more complex expression can be derived. Let $z$ be the integer part of $S$, and $q$ be the fractional part. Then, 


$$
\begin{aligned}
I & =(1-q) \operatorname{Pr}\left[H_{i}=0, i=1 \ldots z\right]+g \operatorname{Pr}[H i=0, i=1 \ldots z+1] \\
& =(1-q)\left(\mathrm{e}^{B\left(\mathrm{e}^{-k}-1\right)}\right)^{z}+q\left(\mathrm{e}^{B\left(\mathrm{e}^{-k}-1\right)}\right)^{z+1} \\
& =\left(\mathrm{e}^{B\left(\mathrm{e}^{-k}-1\right)}\right)^{-q}\left(\mathrm{e}^{B\left(\mathrm{e}^{-k}-1\right)}\right) S\left[1+q\left(\mathrm{e}^{B\left(\mathrm{e}^{-k}-1\right)}-1\right)\right] .
\end{aligned}
$$

The term in square brackets is a first-order Taylor approximation,

$$
1+q(x-1) \approx x ?
$$

where $x=e^{B\left(e_{-A}^{-1}\right)}$, which means that Eq. A.8 can be used as an approximation for Eq. A.10.

It is also possible to derive an expression for $B$ as a function of $A, S$, and $I$. This is useful for generating probability contours, such as the critical thresholds in Figs. 2 and 3. Let $I$ be the value of the contour, and using Eq. A.8, solve for $B$ to get

$$
B=\frac{\ln (I)}{S\left(e^{-A}-1\right)}
$$

For small $A$, the expression $e^{-A}$ can be approximated by a Taylor series, $1-A$, and $B$ at the threshold is

$$
B \approx \frac{-\ln (T)}{S A}
$$

On $\log$ scales for $A$ and $B$, this relationship is

$$
\ln (B) \approx \ln \left(\frac{-\ln (I)}{S}\right)-\ln (A)
$$

which is a straight line with slope -1 .

For large $A$, the expression $e^{-A}$ is approximately equal to 0 , and the threshold is

$$
B \approx \frac{-\ln (T)}{S}
$$

At the critical threshold, $I=0.05$, and the expression is $\ln (20) / S$.

Case 2: $a_{i, j}$ is Poisson distributed, and $b_{i}$ is negative-binomially distributed.

Start with a negative binomial having the conventional parameters $m$ and $p$. The probability of zero habitat in an individual year is 


$$
\begin{aligned}
\operatorname{Pr}\left[H_{i}\right. & =0]=\sum_{x=0}^{\infty} \operatorname{Pr}\left[a_{i, i}=0 \text { for all } j \mid b_{i}=x\right] \operatorname{Pr}\left[b_{i}=x\right] \\
& =\sum_{x=0}^{\infty} e^{-A} e^{-A} \ldots e^{-A}\left(\begin{array}{c}
m+x-1 \\
m-1
\end{array}\right) p^{m}(1-p)^{x} \\
& =\sum_{x=0}^{\infty} e^{-A x}\left(\begin{array}{c}
m+x-1 \\
m-1
\end{array}\right) p^{m}(1-p)^{x} \\
& \left.=p^{m} \sum_{x=0}^{\infty}\left(\begin{array}{c}
m+x-1 \\
m-1
\end{array}\right)(1-p) e^{-A}\right]^{x}
\end{aligned}
$$

Let $p^{*}=1-(1-p) e^{-A}$. Multiply each term of the summation by $\left(p^{*}\right)^{m} /\left(p^{*}\right)^{m}$ and factor out the denominator, to obtain

$$
\begin{aligned}
& =p^{m}\left[1-(1-v) e^{-A}\right]^{-m}\left(\sum_{x=0}^{\infty}\left(\begin{array}{c}
m+x-1 \\
m-1
\end{array}\right)\left[(1-p) e^{-A}\right]^{x}\left(p^{*}\right)^{m}\right) \\
& =p^{m}\left[1-(1-v) e^{-A}\right]^{-m}\left(\sum_{x=0}^{\infty}\left(\begin{array}{c}
m+x-1 \\
m-1
\end{array}\right)\left[1-p^{*}\right]^{x}\left(p^{*}\right)^{m}\right) .
\end{aligned}
$$

The summation now contains a negative-binomial PDF with parameters $m$ and $p^{*}$, and therefore it sums to 1 . The expression simplifies to

$$
\operatorname{Pr}\left[H_{i}=0\right]=p^{m}\left[1-(1-p) e^{-A}\right]^{-m} .
$$

Considering all years combined gives

$$
\operatorname{Pr}[H=0]=p^{S m}\left[1-(1-p) e^{-A}\right]^{-S m},
$$

and substituting $B$ and $u$ for $m$ and $p$ produces

$$
I=\left(\frac{1}{1+B u}\right)^{S i u}\left(1-\frac{B u e^{-A}}{1+B u}\right)^{-S i u}
$$

This simplifies further to 


$$
\begin{aligned}
I & =\left(\frac{(1+B u)^{-1}}{1-B u e^{-A}(1+B u)^{-1}}\right)^{s i u} \\
& =\left(\frac{(1+B u)^{-1}}{\left(1+B u-B u e^{-A}\right)(1+B u)^{-1}}\right)^{s i u} \\
& =\left(\frac{1}{\left(1+B u-B u e^{-A}\right.}\right)^{\operatorname{siu}} \\
I & =\left(1+B u-B u e^{-A}\right)^{-s i u}
\end{aligned}
$$

To obtain values for a given contour of $I$, solve for $B$ to obtain

$$
B=\frac{I^{-u / S}-1}{u\left(1-e^{-A}\right)}
$$

which shows the $B$ necessary to attain a given threshold $I$. As in Case 1 above, it is possible to obtain simpler approximations when $A$ is large or small:

$$
\begin{aligned}
& B \approx \frac{T^{-u I S}-1}{u A}, A<0.5 \\
& B \approx \frac{T^{-u I S}-1}{u}, A>2 .
\end{aligned}
$$

Case 3: $a_{i, j}$ is negative-binomially distributed, and $b_{i}$ is Poisson distributed:

$$
\begin{aligned}
\operatorname{Pr}\left[H_{i}\right. & =0]=\sum_{x=0}^{\infty} \operatorname{Pr}\left[a_{i, i}=0 \text { for all } j \mid b_{i}=x\right] \operatorname{Pr}\left[b_{i}=x\right] \\
& =\sum_{x=0}^{\infty} p^{m} p^{m} \ldots p^{m}\left(e^{-B} B^{x} / x !\right) \\
& =\sum_{x=0}^{\infty} p^{m x}\left(e^{-B} B^{x} / x !\right) \\
& =e^{-B} \sum_{x=0}^{\infty}\left(p^{m} B\right)^{x} / x ! \\
& =e^{-B} e^{p^{m} B}=e^{B\left(p^{m}-1\right)}
\end{aligned}
$$

Considering all years gives $I=\exp \left(\left[p^{m}-1\right] B S\right)$, which, after substituting in $A$ and $u$, yields 


$$
I=\exp \left(\left[(1+A u)^{-1 / u}-1\right] B S\right) \text {. }
$$

To get a function for a given contour of $I$, solve for $B$ and obtain

$$
B=\frac{\ln (I)}{S\left[(1+A u)^{-1 w}-1\right]}
$$

Case 4: $a_{i, j}$ and $b_{i}$ are negative-binomially distributed.

The PDF for $a_{i, j}$ has parameters $p_{1}$ and $m_{1}$ and for $b_{i}$ has parameters $p_{2}$ and $m_{2}$ :

$$
\begin{aligned}
\operatorname{Pr}\left[H_{i}\right. & =0]=\sum_{x=0}^{\infty} \operatorname{Pr}\left[a_{i}=0 \text { for all } i \mid b_{i}=x\right] \operatorname{Pr}\left[b_{i}=x\right] \\
& =\sum_{x=0}^{\infty} p_{1}^{m_{1} x}\left(\begin{array}{c}
m_{2}+x-1 \\
m_{2}-1
\end{array}\right)_{2}^{m_{2}}\left(1-p_{2}\right)^{x} \\
& =\sum_{x=0}^{\infty}\left(\begin{array}{c}
m_{2}+x-1 \\
m_{2}-1
\end{array}\right)\left(p_{2}^{m_{1}}\left[p_{1}^{m_{1}}\left(1-p_{2}\right)\right]^{x}\right. \\
& =p_{2}^{m_{2}}\left[1-\left(1-p_{2}\right) p_{1}^{m_{1}}\right]^{-m_{2}} \sum_{x=0}^{\infty}\left(\begin{array}{c}
m_{2}+x-1 \\
m_{2}-1
\end{array}\right)\left[1-\left(1-p_{2}\right) p_{1}^{m_{2}}\right]^{m_{2}}\left(p_{2}^{m_{2}}\left[p_{1}^{m_{1}}\left(1-p_{2}\right)\right]^{x}\right. \\
& =p_{2}^{m_{2}}\left[1-\left(1-p_{2}\right) p_{1}^{m_{1}}\right]^{-m_{2}}
\end{aligned}
$$

The summation is a PDF that sums to 1 . And for all years considered together,

$$
I=\left(1+B u_{B}\right)^{-S i u_{5}}\left[1-\left(\frac{B u_{B}}{1+B u_{B}}\right)\left(1+A u_{A}\right)^{-1 i u_{H}}\right]^{-S i u_{F}}
$$

\section{Disturbance model with patch lifetime $S$}

As before, let $H(t)$ be a random variable for total habitat area at time $t$. The disturbance model assumes that patches have a constant probability of being eliminated, so let $\operatorname{Pr}\left[\right.$ existing patch dies in a given year] $=\frac{1}{S}$. The amount of habitat in year $t$ is

$$
H(t)=\sum_{i=1}^{t} \sum_{i=1}^{b_{1}} H_{i, i}(t)
$$

where $H_{i, j}(t)$ is the amount of habitat in the $j^{t h}$ patch born in the $i^{t h}$ year, that is still present in year $t$. For habitat in a given year, 


$$
\text { Let } H_{i}(t)=\sum_{i=1}^{b_{1}} H_{i, i}(t)
$$

Then the probability of zero habitat in year $t$ is

$$
\begin{aligned}
\operatorname{Pr}[H(t) & =0]=\operatorname{Pr}\left[H_{i}(t)=0 \text { for all } i=1 \ldots t\right] \\
& =\prod_{i=1}^{t} \operatorname{Pr}\left[H_{i}(t)=0\right]
\end{aligned}
$$

and the contribution from each year $i$ is

$$
\begin{aligned}
\operatorname{Pr}\left[H_{i}(t)\right. & =0]=\operatorname{Pr}\left[H_{i, i}(t)=0 \text { for all } j=1 \ldots b_{i}\right] \\
& =\prod_{i=1}^{b_{1}} \operatorname{Pr}\left[H_{i, i}(t)=0\right] .
\end{aligned}
$$

The probability for each patch in each year is

$$
\operatorname{Pr}\left[H_{i, i}(t)=0\right]=\operatorname{Pr}\left[a_{i, i}=0\right]+\operatorname{Pr}\left[a_{i, i}>0\right] \operatorname{Pr}\left[H_{i, i}(t)=0 \mid a_{i, i}>0\right]
$$

This final equation states that there are two ways in which a patch can have size zero when it is $t-i$ years old: (1) when it is born, the random variable that determines its size is 0 , or (2) it is born with positive size but gets disturbed at some time during the following $t-i$ years. For an existing site, the probability that it does not get disturbed in $t-i$ years is $\left(1-\frac{1}{S}\right)^{t-i}$. Therefore, we can write

$$
\operatorname{Pr}\left[H_{i, i}(t)=0\right]=\operatorname{Pr}\left[a_{i, i}=0\right]+\operatorname{Pr}\left[a_{i, i}>0\right]\left[1-\left(1-\frac{1}{s^{\prime}}\right)^{t-i}\right]
$$

Consequently, the probability for each year $i$ is

$$
\begin{aligned}
\operatorname{Pr}\left[H_{i}(t)\right. & =0]=\prod_{i=1}^{b_{1}} \operatorname{Pr}\left[a_{i, i}=0\right]+\operatorname{Pr}\left[a_{i, i}>0\right]\left[1-\left(1-\frac{1}{s}\right)^{i-i}\right] \\
& =\left(\operatorname{Pr}\left[a_{i, i}=0\right]+\operatorname{Pr}\left[a_{i, i}>0\right]\left[1-\left(1-\frac{1}{s}\right)^{t-i}\right]\right)^{b_{1}} \\
& =\sum_{x=0}^{\infty}\left(\operatorname{Pr}\left[a_{i, i}=0\right]+\operatorname{Pr}\left[a_{i, i}>0\right]\left[1-\left(1-\frac{1}{s}\right)^{t-i}\right]\right)^{x} \operatorname{Pr}\left[b_{i}=x\right]
\end{aligned}
$$

This final equation can be combined with any of the PDFs of $a_{i, j}$ and $b_{i}$ to determine the PDF of $H_{i}(t)$, and therefore of $H(t)$.

Case 1: $a_{i, j}$ and $b_{i}$ are Poisson distributed with means $A$ and $B$.

Substituting the proper PDFs, and using the same techniques as above, we get 


$$
\operatorname{Pr}\left[H_{i}(t)=0\right]=\exp \left\{-B+B\left[e^{-A}+\left(1-e^{-A}\right)\left(1-\left(1-\frac{1}{S}\right)^{t-i}\right)\right]\right\},
$$

and, for all years combined,

$$
\begin{aligned}
I & =\prod_{i=1}^{t} \exp \left\{-B+B\left[e^{-A}+\left(1-e^{-A}\right)\left(1-\left(1-\frac{1}{S}\right)^{t-i}\right)\right]\right. \\
& =\prod_{i=1}^{t} \exp \left\{-B+B\left[e^{-A}+\left(1-e^{-A}\right)\right]-B\left(1-e^{-A}\right)\left(1-\frac{1}{S}\right)^{t-i}\right\} \\
& =\prod_{i=1}^{t} \exp \left\{-B\left(1-e^{-A}\right)\left(1-\frac{1}{S}\right)^{t-i}\right\} \\
& =\exp \left\{-B\left(1-e^{-A}\right) \sum_{i=0}^{t}\left(1-\frac{1}{S}\right)^{t}\right\} \\
& =\exp \left\{-B\left(1-e^{-A}\right) \frac{1-\left(1-\frac{1}{S}\right)^{t}}{1-\left(1-\frac{1}{S}\right)}\right\}
\end{aligned}
$$

To approximate a probability that covers a very long time span, take the limit as $t$ approaches infinity. Because $S$ $>1$, the limit of $\left(1-\frac{1}{S}\right)^{t}$ is zero, and the above expression simplifies to

$$
I=\exp \left\{B\left(e^{-A}-1\right)\right\}
$$

which is equivalent to Eq. A.8. To obtain a given contour of $I$, solve for $B$ to obtain

$$
B=\frac{\ln (I)}{S\left(e^{-A}-1\right)}
$$

Compare this result to Eq. A.11. As in the case for the succession mode, approximations in disturbance mode can be developed for large and small $A$, giving

$$
B \approx \frac{-\ln (I)}{S A}
$$

for small $A$, and

$$
B \approx \frac{-\ln (I)}{S}
$$

for large $A$.

For the first of the above two equations, the slope of $B$ vs. $A$ on a $\log -\log$ scale is -1 ; for the second, $B$ is independent of $A$. 
Case 2: $a_{i, j}$ is Poisson distributed, and $b_{i}$ is negative-binomially distributed.

The probability for one year is

$$
\operatorname{Pr}\left[H_{i}(t)=0\right]=p^{m}[1-(1-p) K]^{-m},
$$

where $K=\mathrm{e}^{-A}+\left(1-\mathrm{e}^{-A}\right)\left(1-\left(1-\frac{1}{S}\right)^{t-i}\right)$.

The probability for all years is

$$
\begin{aligned}
I & =p^{m t} \prod_{i=1}^{t}[1-(1-p) K]^{-m} \\
& =\exp \left\{m\left[t \ln (p)-\sum_{i=1}^{t} \ln (1-(1-p) K)\right]\right\}
\end{aligned}
$$

The latter form is often more convenient to compute when $t$ is large. Substituting in $B$ and $u$ yields the final equation

$$
I=\exp \left\{\frac{-t \ln (1+B u)-\sum_{i=1}^{t} \ln \left[1-\left(\frac{B u}{1+B u}\right)\left(e^{-A}+\left(1-e^{-A}\right)\left(1-\left(1-\frac{1}{s}\right)^{i-i}\right)\right)\right]}{u}\right\}
$$

Case 3: $a_{i, j}$ is negative-binomially distributed, and $b_{i}$ is Poisson distributed.

The derivation is similar to that of Case 1 , with $p^{m}$ substituted for $e^{-A}$.

$$
\begin{aligned}
& \operatorname{Pr}\left[H_{i}(t)=0\right]=\exp \left\{-B+B\left[p^{m}+\left(1-p^{m}\right)\left(1-\left(1-\frac{1}{S}\right)^{t-i}\right)\right]\right\} \\
I= & \exp \left\{S B\left(p^{m}-1\right)\right\}(\text { taking the limit of } t \text { approaching infinity }) \\
= & \exp \left\{S B\left(1-(1+u A)^{-1 / u}\right)\right\} .
\end{aligned}
$$

Case 4: $a_{i, j}$ and $b_{i}$ are negative-binomially distributed.

Probability for year $i$ is

$$
\operatorname{Pr}\left[H_{i}(t)=0\right]=p_{2}^{m 1}\left(1-\left(1-p_{2}\right) \mathrm{K}\right)^{-m 1},
$$

where $K=p_{1}{ }^{m 1}+\left(1-p_{1}{ }^{m 1}\right)\left(1-\left(1-\frac{1}{\mathcal{S}}\right)^{t-i}\right.$.

Probability for all years,

$$
\begin{aligned}
I & =\prod_{i=1}^{t} p_{2}^{m_{1}}\left(1-\left(1-p_{2}\right) K\right)^{-m_{i}} \\
& =\left(1+u_{B} B\right)^{-i u_{B}} \prod_{i=1}^{t}\left(1-\left(\frac{u_{B} B}{1+u_{B} B}\right) K\right)^{-1 i u_{B}},
\end{aligned}
$$


where $K=\left(1+u_{A} A\right)^{-1 / u}{ }_{A}+\left(1-\left(1+u_{A} A\right)^{-1 / u}{ }_{A}\right)\left(1-\left(1-\frac{1}{S}\right)^{t-i}\right)$.

\section{Specifying $t$}

In practice, $t$ should be large enough that the effects of initial conditions are negligible. Let $g$ be the probability that patches appearing at time zero have disappeared by time $t$. This probability becomes smaller as $t$ increases, so in practice the best procedure is to choose a time span sufficiently large that the impact of initial conditions is small (i.e., a value for $g$ that is arbitrarily close to 1). From Eq. A.34 it is possible to derive the expression

$$
g=\left(1-\left(1-\frac{1}{g}\right)^{+1}\right)
$$

in which the number of patch births in year 0 is assumed to equal $B$. Solving for $t$ gives

$$
t=\frac{\log \left[1-g^{1 / 9}\right]}{\log \left[1-\frac{1}{g}\right]}-1
$$

In our calculations we used $g=0.9999$. For example, if $S$ was $100 \mathrm{yr}$ and $B$ was 100 patch births per year, then to obtain a $g$ of 0.9999 we used $t=1375 \mathrm{yr}$.

\section{Mean and variance effects}

A simulation was used to estimate mean and variance effects. Random variables $b_{i}, a_{i, j}$, and $s_{i, j}$ were numerically sampled from a random number generator. The generator was the Marsenne Twister, invented by Matsumoto and Nishimura (1998) and published on the Internet at http://www.math.keio.ac.jp/ matumoto/emt.html. Its uniformly distributed numbers were transformed to Poisson and negative-binomially distributed numbers using algorithms from L'Ecuyer and Côté (1991); coded into C by B.W. Brown, J. Lovato, and K. Russell; and published on the internet at http://www.netlib.org/random/. The algorithm used to simulate patch dynamics had the following steps:

1. Specify the number of years $t$ to run the model (see below).

2. Specify the parameters of the distributions $B, S, A, u_{B}$, and $u_{A}$ and whether the succession or disturbance model is used.

3. Generate a vector $\mathbf{x}$ of patch birth times: sample $t$ random values of $b_{i}$ from the appropriate distribution (Poisson, negative binomial). This is the number of patch births in each year. The total number of patches is $M=S b_{i}$. Convert the vector for patch births of each $t$ to a vector for birth times $\left(x_{m}\right)$ of each patch (for example, three births at $t=4$ is converted to the vector $\{4,4,4\})$.

4. Generate a vector $\mathbf{y}$ of patch disappearance times: sample $M$ random lifetimes $s_{m}$ from the appropriate distribution (regular or geometric). Add the vector of lifetimes to the vector $\mathbf{x}$ to get a vector of disappearance times $y_{m}$.

5. Generate a vector $\mathbf{z}$ of patch sizes: sample $M$ random sizes $z_{m}$ from the appropriate distribution (Poisson or negative binomial).

6. Simulate patchy population or metapopulation dynamics in the set of patches characterized by the vectors $\mathbf{x}, \mathbf{y}$, and $\mathbf{z}$.

\section{Derivation of metapopulation equation}

The parameter of the metapopulation model is $c$, the probability that an organism in one patch will send out 
propagules that successfully colonize another patch. Once established, the new population is assumed to immediately grow to local carrying capacity and to persist until the patch disappears. To derive the equation, consider colonization of patch $i$ by organisms from patch $j$. If the probability for one organism is $c$, then the probability for all organisms in the patch is $1-(1-c)^{a}$, in which $a$ is the size of patch $j$ and colonization by each organism is assumed to be independent of the others. Combining across all patches gives

$$
D_{i, t}=1-\prod_{j}^{M}\left\{1-p_{j, t}\left(1-(1-c)^{a_{j}}\right)\right\} j \neq i
$$

in which $D_{i, t}$ is the probability that patch $i$ will be colonized during year $t$; independence among patches is assumed. The value $p_{j, t}$ is the probability that patch $j$ will be occupied in year $t$. The metapopulation equation is simply

$$
\underline{D}_{i, t+1}=D_{i, t}+\left(1-\underline{D}_{i, t}\right) D_{i, t}
$$

which is inserted into the simulation model described above.

\section{Numerical methods}

To do the simulations, species abundances were initialized at carrying capacity and projected forward using Eqs. 3 and 4 . The length of the run $t$ was $2 s$ yr to allow the patch dynamics to reach an approximately stationary state; a period of $100 \mathrm{yr}$ was then added to quantify effect sizes. Each parameter combination was run 100+ times; effect size was estimated as the mean of all runs. In general, enough runs were performed to make the standard error of effect size negligible.

The procedure was computationally intensive. It was impractical to make the estimates over 12 orders of magnitude of $A$ and $B$, as was done for the gap effect. Instead, we examined a single value of $A$ (mean patch size $=10$ ). The analysis of the gap effect suggested that this was sufficient, because risk was relatively insensitive to changes in $A$ for values greater than $A=2$ (see Results). For patch birth rate $B$, we examined a range of values as described in the results that ranged from the critical threshold up to 10,000 .

\section{LITERATURE CITED}

Amarasekare, P., and H. Possingham. 2001. Patch dynamics and metapopulation theory: the case of successional species. Journal of Theoretical Biology 209:333-344.

Aplet, G. H., and W. S. Keeton. 1999. Application of historical range of variability concepts to biodiversity conservation. Pages 71-86 in R. K. Baydack, H. Campa III, and J. B. Haufler, editors. Practical approaches to the conservation of biodiversity. Island Press, Washington, D.C., USA.

Attiwill, P. M. 1994. The disturbance of forest ecosystems: the ecological basis for conservative management. Forest Ecology and Management 63:247-300.

Baker, W. L. 1992. The landscape ecology of large disturbances in the design and management of nature reserves. Landscape Ecology 7:181-194.

Benda, L. E., D. J. Miller, T. Dunne, G. H. Reeves, and J. K. Agee. 1995. Dynamic landscape systems. Pages 261-
288 in J. L. Nielsen, editor. Evolution and the aquatic ecosystem: defining unique units in population conservation. American Fisheries Society, Bethesda, Maryland, USA.

Boughton, D. A., E. R. Smith, and R. V. O'Neill. 1999. Regional vulnerability: a conceptual framework. Ecosystem Health 5:312-322.

Brachet, S., I. Olivieri, B. Godelle, E. Klein, N. Frascaria-Lacoste, and P.-H. Gouyon. 1999. Dispersal and metapopulation viability in a heterogeneous landscape. Journal of Theoretical Biology 198:479-495.

Busing, R. T., and P. S. White. 1993. Effects of area on old-growth forest attributes: implications for the equilibrium landscape concept. Landscape Ecology 8:119-126.

Cissel, J. H., F. J. Swanson, and P. J. Weisberg. 1999. Landscape management using historical fire regimes: Blue River, Oregon. Ecological Applications 9:1217-1231.

Clark, J. S. 1993. Shifting mosaic population dynamics. Pages 224-246 in S. Levin, T. M. Powell, and J. H. Steele, 
editors. Patch dynamics. Springer Verlag, New York, New York, USA.

Clark, J. S. 1996. Testing disturbance theory with longterm data: alternative life history solutions to the distribution of events. American Naturalist 148:976-996.

Easterling, D. R., G. A. Meehl, C. Parmesan, S. A. Changnon, T. R. Karl, and L. O. Mearns. 2000. Climate extremes: observations, modeling, and impacts. Science 289:2068-2074.

Engels, T. M., and C. W. Sexton. 1994. Negative correlation of blue jays and golden-cheeked warblers near an urbanizing area. Conservation Biology 8:286-290.

Everett, R. L., and J. F. Lehmkuhl. 1999. Restoring biodiversity on public forest lands through disturbance and patch management irrespective of land-use allocation. Pages 87-105 in R. K. Baydack, H. Campa III, and J. B. Haufler, editors. Practical approaches to the conservation of biodiversity. Island Press, Washington, D.C., USA.

Fahrig, L. 1992. Relative importance of spatial and temporal scales in a patchy environment. Theoretical Population Biology 41:300-314.

Foley, P. 1997. Extinction models for local populations. Pages 215-245 in I. A. Hanski and M. E. Gilpin, editors. Metapopulation biology: ecology, genetics, and evolution. Academic Press, San Diego, California, USA.

Frissell, C. A., and D. Byles. 1996. Ecosystem management and the conservation of aquatic biodiversity and ecological integrity. Water Resources Bulletin 32:229240 .

Grzybowski, J. A., D. J. Tazik, and G. D. Schnell. 1994. Regional analysis of black capped vireo breeding habitats. Condor 96:512-544.

Gyllenberg, M., and I. Hanski. 1997. Habitat deterioration, habitat destruction, and metapopulation persistence in a heterogenous landscape. Theoretical Population Biology 52:198-215.

Hanski, I. 1990. Density dependence, regulation and variability in animal populations. Philosophical Transactions of the Royal Society of London B 330:141-150.

Hanski, I. 1991. Single-species metapopulation dynamics: concepts, models and observations. Pages 17-38 in I. Hanski and M. E. Gilpin, editors. Metapopulation biology: ecology, genetics, and evolution. Academic Press, San Diego, California, USA.

Hanski, I. 1994. A practical model of metapopulation dynamics. Journal of Animal Ecology 63:151-162.

Hanski, I., and M. E. Gilpin. 1997. Metapopulation biology: ecology, genetics, and evolution. Academic Press, San Diego, California, USA.
Harrison, S. 1991. Local extinction in a metapopulation context: an empirical evaluation. Biological Journal of the Linnean Society 42:73-88.

Hilborn, R., and M. Mangel. 1997. The ecological detective: confronting models with data. Princeton University Press, Princeton, New Jersey, USA.

Holt, R. D. 1992. A neglected facet of island biogeography: the role of internal spatial dynamics in area effects. Theoretical Population Biology 41:354-371.

Hutchinson, G. E. 1958. Concluding remarks. Cold Spring Harbor Symposia on Quantitative Biology 22:415-427.

Intergovernmental Panel on Climate Change. 2000. Intergovernmental Panel on Climate Change Working Group I-third assessment report. IPCC, World Meteorological Organization, Geneva, Switzerland.

Intergovernmental Panel on Climate Change. 2001. Intergovernmental Panel on Climate Change Working Group II-third assessment report. IPCC, World Meteorological Organization, Geneva, Switzerland.

Johnson, M. P. 2000. The influence of patch demographics on metapopulations, with particular reference to successional landscapes. Oikos 88:67-74.

Keymer, J. E., P. A. Marquet, J. X. Velasco-Hernandez, and S. A. Levin. 2000. Extinction thresholds and metapopulation persistence in dynamic landscapes. American Naturalist 156:478-494.

Kohm, A., and J. F. Franklin, editors. 1997. Creating a forestry habitat for the 21st century: the science of ecosystem management. Island Press, Washington, D.C., USA.

Lande, R. 1987. Extinction thresholds in demographic models of territorial populations. American Naturalist 130:624-635.

Lande, R. 1993. Risks of population extinction from demographic and environmental stochasticity and random catastrophes. American Naturalist 142:911-927.

Landres, P. B., P. Morgan, and F. J. Swanson. 1999. Overview of the use of natural variability concepts in managing ecological systems. Ecological Applications 9:1179-1188.

L'Ecuyer, P., and S. Côté. 1991. Implementing a random number package with splitting facilities. ACM Transactions on Mathematical Software 17:98-111.

Levin, S. A., and R. T. Paine. 1974. Disturbance, patch formation, and community structure. Proceedings of the National Academy of Sciences 71:2744-2747.

Levins, R. 1969. Some demographic and genetic consequences of environmental heterogeneity for biological 
control. Bulletin of the Entomological Society of America 15:237-240.

MacArthur, R. H., and E. O. Wilson. 1967. The theory of island biogeography. Princeton University Press, Princeton, New Jersey, USA.

Malamud, B. D., G. Morein, and D. L. Turcotte. 1998. Forest fires: an example of self-organized critical behavior. Science 281:1840-1842.

Matsumoto, M., and T. Nishimura. 1998. Mersenne Twister: a 623-dimensionally equidistributed uniform pseudorandom number generator. ACM Transactions on Modeling and Computer Simulation 8:3-30.

Menges, E. S. 1990. Population viability analysis for an endangered plant. Conservation Biology 4:52-62.

Mountford, M. D. 1988. Population regulation, density dependence, and heterogeneity. Journal of Animal Ecology 57:845-858.

Murdoch, W. W., and S. J. Walde. 1989. Analysis of insect population dynamics. Pages 113-140 in P. J. Grubb and J. B. Whittaker, editors. Toward a more exact ecology. Blackwell, Oxford, UK.

O'Neill, R. V., D. L. DeAngelis, J. B. Waide, and T. F. H. Allen. 1986. A hierarchical concept of ecosystems. Princeton University Press, Princeton, New Jersey, USA.

Paine, R. T., and S. A. Levin. 1981. Intertidal landscapes: disturbance and the dynamics of pattern. Ecological Monographs 51:145-178.

Pickett, S. T. A., and J. N. Thompson. 1978. Patch dynamics and the design of nature reserves. Biological Conservation 13:27-37.

Quinn, J. F., and S. P. Harrison. 1988. Effects of habitat fragmentation and isolation on species richness: evidence from biogeographic patterns. Oecologia 75:132-140.

Shaffer, M. L. 1981. Minimum population sizes for species conservation. BioScience 31:131-134.

Shaffer, M. L. 1987. Minimum viable populations: coping with uncertainty. Pages 69-86 in M. E. Soule, editor. Viable populations for conservation. Cambridge University Press, Cambridge, UK.
Southwood, T. R. E. 1966. Ecological methods, with particular reference to the study of insect populations. Chapman and Hall, London, UK.

Spies, T. A., G. H. Reeves, K. M. Burnett, W. C. McComb, K. N. Johnson, G. Grant, J. L. Ohmann, S. L. Garman, and $\mathbf{P}$. Bettinger. In press. Assessing the ecological consequences of forest policies in a multiownership province in Oregon. In J. Liu and W. W.Taylor, editors. Integrating landscape ecology into natural resource management. Cambridge University Press, Cambridge, UK.

Stelter, C., M. Reich, V. Grimm, and C. Wissel. 1997. Modelling persistence in dynamic landscapes: lessons from a metapopulation of the grasshopper Bryodema tuberculata. Journal of Animal Ecology 66:508-518.

Swanson, F. J., J. A. Jones, D. O. Wallin, and J. H Cissel. 1994. Natural variability-implications for ecosystem management. Pages 80-94 in R. Everett. Eastside forest ecosystem health. Volume 2. U.S. Forest Service PNWGTR-318.

Thomas, J. A., and M. G. Morris. 1994. Patterns, mechanisms and rates of extinction among UK invertebrates. Philosophical Transactions of the Royal Society of London B 344:47-54.

Turner, M. G., W. H. Romme, R. H. Gardner, R. V. O'Neill, and T. K. Kratz. 1993. A revised concept of landscape equilibrium: disturbance and stability on scaled landscapes. Landscape Ecology 8:213-227.

U.S. Forest Service and U.S. Department of the Interior. 1994. Final supplemental environmental impact statement on management of habitat for late-successional and oldgrowth forest related species within the range of the Northern Spotted Owl. Volume 1. U.S. Government Printing Office, Portland, Oregon, USA.

Wimberly, M. C., T. A. Spies, C. J. Jong, and C. Whitlock. 2000. Simulating historical variability in the amount of old forests in the Oregon Coast Range. Conservation Biology 14:167 - 180.

Young, L. J., and J. H. Young. 1998. Statistical ecology: a population perspective. Kluwer Academic, Boston, Massachusetts, USA. 